\title{
BMJ Open Are self-reported unhealthy food choices associated with an increased risk of breast cancer? Prospective cohort study using the British Food Standards Agency nutrient profiling system
}

\author{
Mélanie Deschasaux, ${ }^{1,2}$ Chantal Julia, ${ }^{1,3}$ Emmanuelle Kesse-Guyot, ${ }^{1,2}$ \\ Lucie Lécuyer, ${ }^{1,2}$ Solia Adriouch, ${ }^{1}$ Caroline Méjean, ${ }^{1}$ Pauline Ducrot, ${ }^{1}$ \\ Sandrine Péneau, ${ }^{1}$ Paule Latino-Martel, ${ }^{1,2}$ Léopold K Fezeu, ${ }^{1}$ Philippine Fassier, ${ }^{1,2}$ \\ Serge Hercberg, ${ }^{1,2,3}$ Mathilde Touvier ${ }^{1,2}$
}

To cite: Deschasaux M, Julia C, Kesse-Guyot E, et al. Are self-reported unhealthy food choices associated with an increased risk of breast cancer? Prospective cohort study using the British Food Standards Agency nutrient profiling system. BMJ Open 2017;7:e013718. doi:10.1136/ bmjopen-2016-013718

- Prepublication history and additional material are published online only. To view please visit the journal online (http://dx.doi. org/10.1136/10.1136/bmjopen2016-013718).

Received 1 August 2016 Revised 8 March 2017 Accepted 9 March 2017

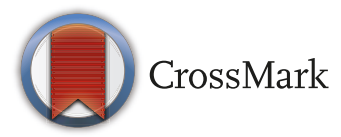

${ }^{1}$ Sorbonne Paris Cité Epidemiology and Statistics Research Center (CRESS), U1153 Inserm, U1125, Inra, Cnam, Paris 13 University, Nutritional Epidemiology Research Team (EREN), Bobigny, France

${ }^{2}$ French network for Nutrition And Cancer Research (NACRe network), www.inra.fr/nacre ${ }^{3}$ Public Health Department, Avicenne Hospital, Bobigny, France

\section{Correspondence to}

Dr. Mélanie Deschasaux; m. deschasaux@eren.smbh.univparis13.fr

\section{ABSTRACT}

Objectives French authorities are considering the implementation of a simplified nutrition labelling system on food products to help consumers make healthier food choices. One of the most documented candidates (Five-Colour Nutrition Label/Nutri-score) is based on the British Food Standards Agency Nutrient Profiling System (FSA-NPS), a score calculated for each food/beverage using the $100 \mathrm{~g}$ amount of energy, sugar, saturated fatty acid, sodium, fibres, proteins, and fruits and vegetables. To assess its potential public health relevance, studies were conducted on the association between the nutritional quality of the diet, measured at the individual level by an energy-weighted mean of all FSA-NPS scores of foods usually consumed (FSA-NPS dietary index (FSA-NPS DI)), and the risk of chronic diseases. The present study aimed at investigating the relationship between the FSA-NPS DI and breast cancer risk.

Design Prospective study.

Setting Population based, NutriNet-Santé cohort, France. Participants 46864 women aged $\geq 35$ years who completed $\geq 3$ 24-hour dietary records during their first 2 year of follow-up.

Primary outcome measure Associations between FSANPS DI and breast cancer risk (555 incident breast cancers diagnosed between 2009 and 2015) were characterised by multivariable-adjusted Cox proportional hazard models. Results A higher FSA-NPS DI (lower nutritional quality of the diet) was associated with an increased breast cancer risk $\left(\mathrm{HR}_{1 \text {-point increment }}=1.06(1.02-1.11), \mathrm{p}=0.005 ; \mathrm{HR}_{\text {a5vs. }}\right.$. ${ }_{Q 1}=1.52(1.11-2.08), p$ trend $\left.=0.002\right)$. Similar trends were observed in premenopausal and postmenopausal women

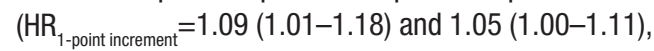
respectively). This study was based on an observational cohort using self-reported dietary data, thus residual confounding cannot be entirely ruled out. Finally, this holistic approach does not allow investigating which factors in the diet most specifically influence breast cancer risk.

Conclusions These results suggested that unhealthy food choices, as characterised by the FSA-NPS, may

\section{Strengths and limitations of this study}

- This study examined the association between an indicator of the overall nutritional quality of the diet based on the Food Standards Agency Nutrient Profiling System (FSA-NPS DI) and the incidence of breast cancer using data from a large prospective cohort study, NutriNet-Santé.

- Dietary intakes were assessed using repeated 24-hour dietary records based on a recent food composition database with a large choice of items (>3300) allowing a better insight into the food products consumed and their intrinsic nutritional composition.

- Unlike other a priori scores, components of the FSA-NPS DI cannot be studied separately since the FSA-NPS DI is first calculated at the food level (FSANPS) and then aggregated at the individual level. In addition, the calculation of the FSA-NPS score (online supplementary file 1) is based on thresholds and is conditional. Thus, the specific contribution of each component of the FSA-NPS DI score to breast cancer risk could not be studied.

- This study included volunteers involved in a longterm cohort study investigating the association between nutrition and health, with overall more health-conscious behaviours and higher professional and/or educational level compared with the general population so that unhealthy dietary behaviours may have been under-represented.

- This study was based on self-declared dietary intakes and on an observational cohort, thus residual confounding cannot be ruled out even though a lot of potential confounders were taken into account.

be associated with an increase in breast cancer risk, supporting the potential public health relevance of using this profiling system in the framework of public health nutritional measures. 


\section{INTRODUCTION}

Breast cancer is the most common female cancer worldwide, with 1.7 million new cases diagnosed in 2012, representing $25 \%$ of all cancers. ${ }^{1}$ According to the estimations of the World Cancer Research Fund/American Institute for Cancer Research (WCRF/AICR), around one-third of breast cancers could be avoided with appropriate diet, body fatness and physical activity. ${ }^{2}$

Nutrition has therefore the potential to be a key factor in breast cancer prevention since it can be modified at the individual level and thus can be targeted by public health policies. To help consumers make healthier food choices, several scientific organisations worldwide have recommended the implementation of a simplified nutrition labelling system on the front-of-pack of food products. ${ }^{3-7}$ In France, a five-colour labelling system (Five-Colour Nutrition Label (5-CNL)) based on the British Food Standards Agency Nutrient Profiling System (FSA-NPS) ${ }^{89}$ has been proposed to summarise the overall nutritional quality of food products. ${ }^{10}$ The FSA-NPS attributes a single score to food products based on a limited number of input variables: amount per $100 \mathrm{~g}$ of energy, total sugars, saturated fatty acids (SFAs), sodium, fruits and vegetables, dietary fibres and proteins. This scoring system was initially developed and validated in the UK, where it is used for advertising regulation, ${ }^{8911} 12$ and it has been adapted and validated in the French context. ${ }^{13-16}$ At the individual level, the nutritional quality of the diet can be characterised with a dietary index based on the FSA-NPS (FSA-NPS DI). The FSA-NPS DI has been associated to food and nutrient intakes, nutritional status and adherence to the French nutritional recommendations. ${ }^{17} 18$

To evaluate the relevance and potential public health impact of the 5-CNL adoption, it is important to assess whether there is a relationship between the nutritional quality of food choices at the individual level, as graded by the FSA-NPS DI, and the occurrence of nutrition-related chronic diseases. To our knowledge, our group was the first to investigate the associations between the FSA-NPS DI and health outcomes. Using prospective designs, studies were conducted in the SU.VI.MAX cohort (13017 participants, 1994-2007) on the associations between the FSA-NPS DI and 13-year weight gain/obesity onset, ${ }^{19}$ metabolic syndrome, ${ }^{20}$ cardiovascular diseases ${ }^{21}$ and cancer. ${ }^{22} \mathrm{~A}$ higher FSA-NPS DI, reflecting a diet of lower nutritional quality, was associated with an increased risk for all the studied outcomes and, in particular, with an increased risk of cancer overall. ${ }^{22}$ No significant association with breast cancer risk was detected in this study, ${ }^{22}$ but the statistical power was limited for site-specific analyses ( $\mathrm{n}=125$ breast cancer cases).

Thus, our objective was to study the association between the FSA-NPS DI (an indicator of the nutritional quality of the diet based on a nutrient profiling system) and breast cancer risk, using data from NutriNet-Santé, a large prospective cohort with up-to-date assessment of dietary intakes.

\section{METHODS}

\section{Study population}

The NutriNet-Santé study is an ongoing French web-based cohort launched in 2009 with the objective to study the associations between nutrition and health as well as the determinants of dietary behaviours and nutritional status. This cohort has been previously described in details. ${ }^{23}$ Participants aged $\geq 18$ years with access to the Internet are continuously recruited since May 2009 among the general population by means of vast multimedia campaigns. All questionnaires are completed online through a dedicated website (www.etude-nutrinet-sante. fr). The NutriNet-Santé study is conducted according to the Declaration of Helsinki guidelines and was approved by the Institutional Review Board of the French Institute for Health and Medical Research (IRB Inserm $\mathrm{n}^{\circ} 0000388 \mathrm{FWA} 00005831$ ) and the 'Commission Nationale de l'Informatique et des Libertés' (CNIL n908450/ $\mathrm{n}^{\circ}$ 909216). Electronic informed consent is obtained from each participant (EudraCT no.2013-000929-31).

\section{Data collection}

At inclusion, participants fulfilled a set of five questionnaires on sociodemographic and lifestyle characteristics ${ }^{24}$ (eg, occupation, educational level, smoking status, alcohol consumption and number of children), anthropomet$\operatorname{rics}^{25} 26$ (eg, height, weight), dietary intakes (see below), physical activity (validated IPAQ questionnaire) ${ }^{27}$ and health status (eg, personal and family history of diseases, medication use including hormonal treatment for menopause and oral contraception and menopausal status). Follow-up of participants began when participants answered their last baseline questionnaire. The date of completion of the last baseline questionnaire is thus used as inclusion date. Participants are then invited to complete these five baseline questionnaires every year as part of the follow-up.

Dietary intakes were assessed at baseline and every 6 months through series of three non-consecutive validated web-based 24-hour dietary records, randomly assigned over a 2-week period (two weekdays and one weekend day). ${ }^{28-30}$ Thus, over the first 2 years of follow-up, up to five series of three 24-hour dietary records could have been completed. To be considered as valid, a series must have included at least two out of three 24-hour dietary records. Participants used a dedicated interface of the study website to declare all foods and beverages consumed during a 24-hour period: three main meals (breakfast, lunch and dinner) or any other eating occasion. Portion sizes were estimated using validated photographs. ${ }^{31}$ Mean daily energy, alcohol and nutrient intakes were estimated using a published French food composition table $(>3300 \text { items })^{32}$ and a weighting for weekdays and weekend days. Amounts consumed from composite dishes were estimated using French recipes validated by food and nutrition professionals. Dietary under-reporting was identified on the basis of the method proposed by Black. ${ }^{33}$ 


\section{FSA-NPS DI computation}

As described previously, ${ }^{9} 1334$ the FSA-NPS score for all foods (processed and unprocessed) and beverages was computed based on the nutrient content for $100 \mathrm{~g}$. FSA-NPS scores for foods and beverages are based on a discrete continuous scale from -15 (most healthy) to +40 (less healthy) (online supplementary file 1). FSA-NPS score allocates points $(0-10)$ for the amount of energy $(\mathrm{kJ})$, total sugar $(\mathrm{g})$, SFA (g) and sodium (mg). Points $(0-5)$ are subtracted from the previous sum based on the amount of fruits and vegetables (\%, including legumes and nuts), fibres (g) and proteins ( $\mathrm{g}$ ). Specific modifications of the score for particular food groups were made to maintain a high consistency with French nutritional recommendations, as proposed by the French High Council for Public Health. ${ }^{34}$

In a second step, the FSA-NPS DI was computed at the individual level using arithmetic energy-weighted means with the following equation, ${ }^{17}$ in which $\mathrm{FS}_{\mathrm{i}}$ represents the food (or beverage) score, and $\mathrm{E}_{\mathrm{i}}$ represents the energy intake from this food or beverage (all 24-hour dietary records from the first 2 years of follow-up were averaged to a mean 24 hours energy intake from this food/beverage):

$$
\text { FSA }- \text { NPS DI }=\frac{\sum_{i=1}^{n} F_{i} E_{i}}{\sum_{i=1}^{n} E_{i}}
$$

Increasing FSA-NPS DI reflects decreasing nutritional quality of foods consumed.

\section{Case ascertainment}

Participants self-declared health events through the yearly health status questionnaire, through a specific check-up questionnaire for health events (every 3 months) or at any time through a dedicated interface on the study website. Following this declaration, participants are invited to send their medical records (diagnosis, hospitalisation and so on) and, if necessary, the study physicians contact the participants' treating physician or the medical structures to collect additional information. Then, data are reviewed by an independent physician expert committee, which validates all major health events (such as cancers). Cancer cases were classified using the International Chronic Diseases Classification, 10th Revision, Clinical Modification. ${ }^{35}$ In this study, all first primary breast cancers diagnosed between the inclusion and August 2015 were considered as cases. Information on death and cause of death was obtained through linkage to the national database on mortality of the French population. ${ }^{36}$

\section{Statistical analyses}

So far, 77034 women without cancer at baseline provided at least three valid 24-hour dietary records during their first 2 years of follow-up. Women aged $<35$ years at baseline $(n=29249)$ were excluded due to a very low susceptibility to develop breast cancer in these women ${ }^{37}$ and a potentially limited influence of nutrition on breast cancers diagnosed in young women. Women with a null follow-up were also excluded from the analyses (ie, women for whom baseline questionnaires were the last completed questionnaires, $\mathrm{n}=921$ ), thus leaving 46864 women included in the analyses (flowchart in online supplementary file 2).

For each woman, the FSA-NPS DI and usual dietary intakes were calculated using all 24-hour dietary records available in their first 2 years of follow-up. Associations between the FSA-NPS DI (continuous variable and quintiles) and breast cancer risk were characterised (HR and 95\% CI) using multivariable Cox proportional hazards models with age as the primary time variable. We confirmed that the assumptions of proportionality were satisfied through examination of the $\log -\log$ (survival) versus log-time plots. Tests for linear trends were performed with the ordinal score on quintiles of FSA-NPS DI. Women contributed person-time to the model until the date of cancer diagnosis, the date of last completed questionnaire and the date of death or August 2015, whichever occurred first. Women who reported cancer other than breast cancer during the study period were included and censored at the date of diagnosis (except basal cell skin carcinoma, not considered as cancer).

Models were adjusted for classic risk factors for breast cancer: age (timescale), body mass index (BMI) $\left(\mathrm{kg} / \mathrm{m}^{2}\right.$. continuous), height (cm, continuous), physical activity (high, moderate, low, computed following IPAQ recommendations ${ }^{38}$ ), smoking status (never smokers, former smokers, occasional smokers and smokers), number of dietary records (continuous), alcohol intake ( $\mathrm{g} / \mathrm{d}$, continuous), energy intake (without alcohol, g/d, continuous), family history of cancer (yes/no), educational level ( $<$ high school degree, $<2$ years after high school degree and $\geq 2$ years after high school degree), number of biological children (continuous), menopausal status at baseline (premenopause, perimenopause and postmenopause), hormonal treatment for menopause (postmenopausal women, yes/no) and oral contraception use (premenopausal women, yes/no).

Interaction analysis was conducted between BMI and the FSA-NPS DI, and stratified analyses were performed by overweight status (BMI $<$ vs $\geq 25 \mathrm{~kg} / \mathrm{m}^{2}$ ).

Sensitivity analyses were performed including only women that provided at least six 24-hour dietary records during their first 2 years of follow-up or excluding cases diagnosed during their first year of follow-up. Analyses were also performed on invasive breast cancer cases only, by hormonal receptor status of the tumours and by menopausal status. For the latter, women contributed person-time to the 'pre-menopause model' until their age of menopause and to the 'post-menopause model' from their age of menopause. Age at menopause was determined using the yearly health status questionnaires available during the follow-up.

For all covariates except physical activity, $\leq 5 \%$ of values were missing and were imputed to the modal value. For physical activity ( $\mathrm{n}=6328$ missing values), a 'missing class' was introduced into the models. 
All tests were two sided, and $\mathrm{p}<0.05$ was considered statistically significant. SAS V.9.4 was used for the analyses.

\section{RESULTS}

Between May 2009 and August 2015 (median follow-up time: 4.0 years; 174491 person-years), 555 incident breast cancer cases were diagnosed: 171 premenopausal and 384 postmenopausal; $71.4 \%$ ER+/PR+, $14.7 \%$ estrogen receptor (ER)-/progesterone receptor (PR)-, $13.6 \%$ $\mathrm{ER}+/ \mathrm{PR}-, 0.3 \% \mathrm{ER}-/ \mathrm{PR}+$ (data available for 361 cases); $83.6 \%$ invasive and $16.4 \%$ in situ (data available for 463 cases). Mean age at diagnosis was 56.6 years $(\mathrm{SD}=9.2)$ and mean baseline-to-diagnosis time was 2.4 years $(\mathrm{SD}=1.6)$. Mean number of dietary records per participant over their first 2years of follow-up was $5.9(\mathrm{SD}=2.8)$.

In table 1, the characteristics of participants at baseline are described overall and by quintiles of the FSA-NPS DI. Mean FSA-NPS DI was 5.9 (SD=2.2; $\min =-5.8 ; \max =18.1$ ). Women with a higher FSA-NPS DI (diet of lower nutritional quality) were more likely to be young, to smoke, to have a higher educational level and to have higher energy or alcohol intakes. As expected, women in the lowest quintiles of FSA-NPS DI (diet of higher nutritional quality) had overall healthier food intakes: higher intakes of fibre, fruits, vegetables, legume and fish and lower intakes of red and processed meat and lipids.

Compared to women who provided at least three 24-hour dietary records during their first 2 years of follow-up, women who did not (15918 women with a non-null follow-up) were younger, premenopause, were more likely to be overweight/obese, to smoke, to practice physical activity and were less likely to have a family history of cancer or to take a hormonal treatment for menopause (data not tabulated).

Associations between the FSA-NPS DI and breast cancer risk overall and by menopausal status are shown in table 2. A direct association was observed between the FSA-NPS DI and breast cancer risk: $\mathrm{HR}_{\mathrm{Q} 5 \mathrm{vs} . \mathrm{Q1}}=1.52$ (95\% CI 1.11 to 2.08$)$, $\mathrm{p}$ trend $=0.002$; $\mathrm{HR}_{\text {per } 1 \text {-unit incre- }}$ ${ }_{\text {ment }}=1.06$ (1.02-1.11), $\mathrm{p}=0.005$. These associations were similarly observed in premenopausal women $\left(\mathrm{HR}_{\mathrm{O} 5 \mathrm{vs}}\right.$ $\mathrm{Q1}_{1}=2.46(1.27-4.75), \mathrm{p}$ trend $=0.004 ; \mathrm{HR}_{\text {per 1-unit increment }}=1.09$ (1.01-1.18), $\mathrm{p}=0.03)$ and in postmenopausal women $\left(\mathrm{HR}_{\text {Q5vs.Q1 }}=1.25 \quad(0.85-1.84), \mathrm{p}\right.$ trend $=0.09 ; \quad \mathrm{HR}_{\text {per 1-unit }}$ increment $=1.05$ (1.00-1.11), $\mathrm{p}=0.06)$, although the associations seemed stronger for premenopausal women and only trends were observed for postmenopausal women ( $p$ interaction $=0.06)$.

Analyses performed by overweight status showed that associations tended to be stronger in non-overweight women (368 cases/31401 non-cases, $\mathrm{HR}_{\text {Q5vs. }}$ $\mathrm{Q}_{1}=1.97 \quad(95 \%$ CI 1.31 to 2.96$), \mathrm{p}$ trend $=0.0007 ; \mathrm{HR}_{\text {per }}$ 1-unit increment $=1.09(1.03-1.15), \mathrm{p}=0.003)$ compared with overweight/obese women (187 cases/14 908 non-cases, $\mathrm{HR}_{\mathrm{Q} 5 \mathrm{vs} . \mathrm{Q1}}=1.02$ (95\% CI 0.61 to 1.73$)$, $\mathrm{p}$ trend $=0.6 ; \mathrm{HR}_{\mathrm{per}}$ 1-unit increment $=1.03(0.95-1.11), \mathrm{p}=0.5)$, but the interaction was not statistically significant $(\mathrm{p}=0.07)$.
Information regarding hormone receptor status was not available for all cases (ER status: 361 cases, PR status: 362 cases, ER/PR status: 361 cases). Significant direct associations between the FSA-NPS DI and breast cancer risk were observed for breast cancer types PR- (102 cases/46762 non-cases) and ER+/PR- (49 cases/46815 non-cases). For ER+ tumours, the linear trend was not statistically significant $(\mathrm{p}=0.07,307$ cases $/ 46557$ non-cases $)$ but compared with women in the lowest quintile of FSA-NPS DI, those with higher scores had an increased breast cancer risk (eg, $\left.\mathrm{HR}_{\mathrm{Q} 5 \mathrm{vs} . \mathrm{Q} 1}=1.60(1.04-1.46)\right)$. Associations were non-significant for the other hormone receptor status (online supplementary file 3). However, these exploratory findings should be considered with caution due to limited statistical power for analyses by cancer subtypes.

Similar results were observed when analyses excluded cases diagnosed during their first year of follow-up (425 cases/46 309 non-cases included; $\mathrm{HR}_{\mathrm{Q} 5 \mathrm{vs} . \mathrm{Q} 1}=1.54$ (1.082.19), $\mathrm{p}$ trend $=0.007 ; \mathrm{HR}_{\text {per 1-unit increment }}=1.07 \quad(1.02-1.12)$, $\mathrm{p}=0.01$ ) or when analyses were restricted to invasive breast cancers ( 387 cases / 46309 non-cases; $\mathrm{HR}_{\mathrm{Q} \text { svs. Q1 }}=1.51$ $(1.03-2.22), \mathrm{p}$ trend $=0.01 ; \mathrm{HR}_{\text {per 1-unit increment }}=1.06(1.01-$ $1.12), \mathrm{p}=0.03)$.

Results were also similar when analyses were restricted to women that provided at least six 24-hour dietary records during their first 2years of follow-up (399 cases/25 439 non-cases; $\mathrm{HR}_{\mathrm{Q} 5 \mathrm{ss} .01}=1.63$ (1.11-2.38), $\mathrm{p}$ trend $=0.006$; $\left.\mathrm{HR}_{\text {per 1-unit increment }}=1.08(1.02-1.14), \mathrm{p}=0.01\right)$ (data not tabulated).

Finally, similar but weaker trends were observed when women aged $<35$ years at baseline were included in the analyses $\left(585\right.$ cases/74617 non-cases, $\mathrm{HR}_{\mathrm{Q} 5 \mathrm{vs} . \mathrm{Q1}}=1.17$ $(95 \%$ CI 0.83 to 1.64$), p$ trend $=0.1 ; \mathrm{HR}_{\text {per 1-unit increment }}=1.05$ $(1.01-1.10), \mathrm{p}=0.02)$.

\section{DISCUSSION}

In this prospective study conducted in a large sample of women from the French general population, a higher FSA-NPS DI, which reflects a diet composed of food products of lower nutritional quality, was associated with a 52\% increase in breast cancer risk (highest vs lowest quintile of the FSA-NPS DI score).

In a previous study performed in the SU.VI.MAX cohort, ${ }^{22}$ we observed a direct association between the FSA-NPS DI and cancer risk overall but did not detect a significant association for breast cancer risk, probably due to limited power in site-specific analyses ( $\mathrm{n}=125$ breast cancer cases, 13-year follow-up). To our knowledge, no other study investigated the relationship between breast cancer risk and a score that characterises the nutritional quality of an individual's diet based on a nutrient profiling system at the level of foods/beverages consumed.

However, a few studies have been conducted on the association between NPS-based dietary scores and other health outcomes. While in this study, we used the FSA-NPS as a continuous score at the food/beverage 


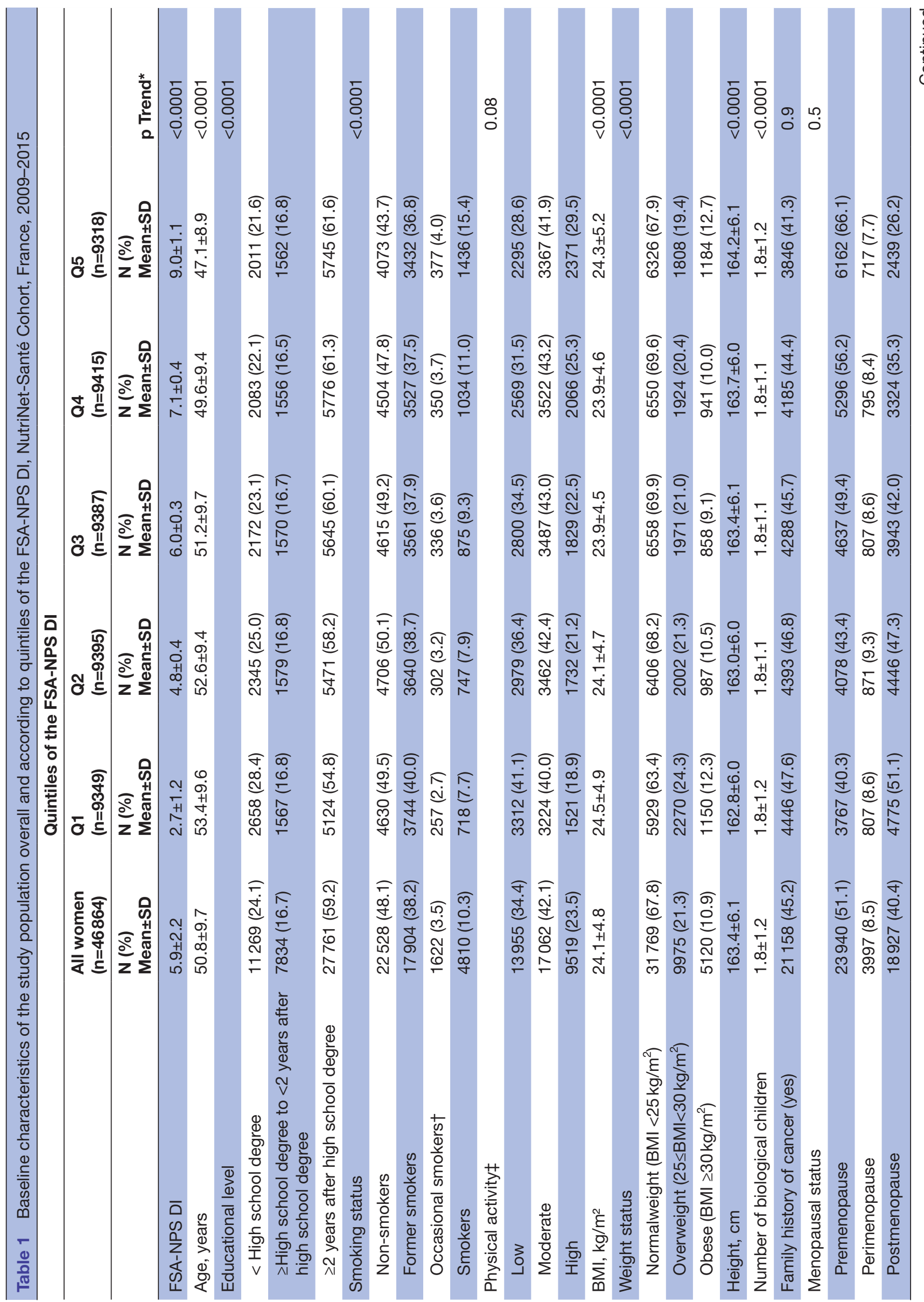




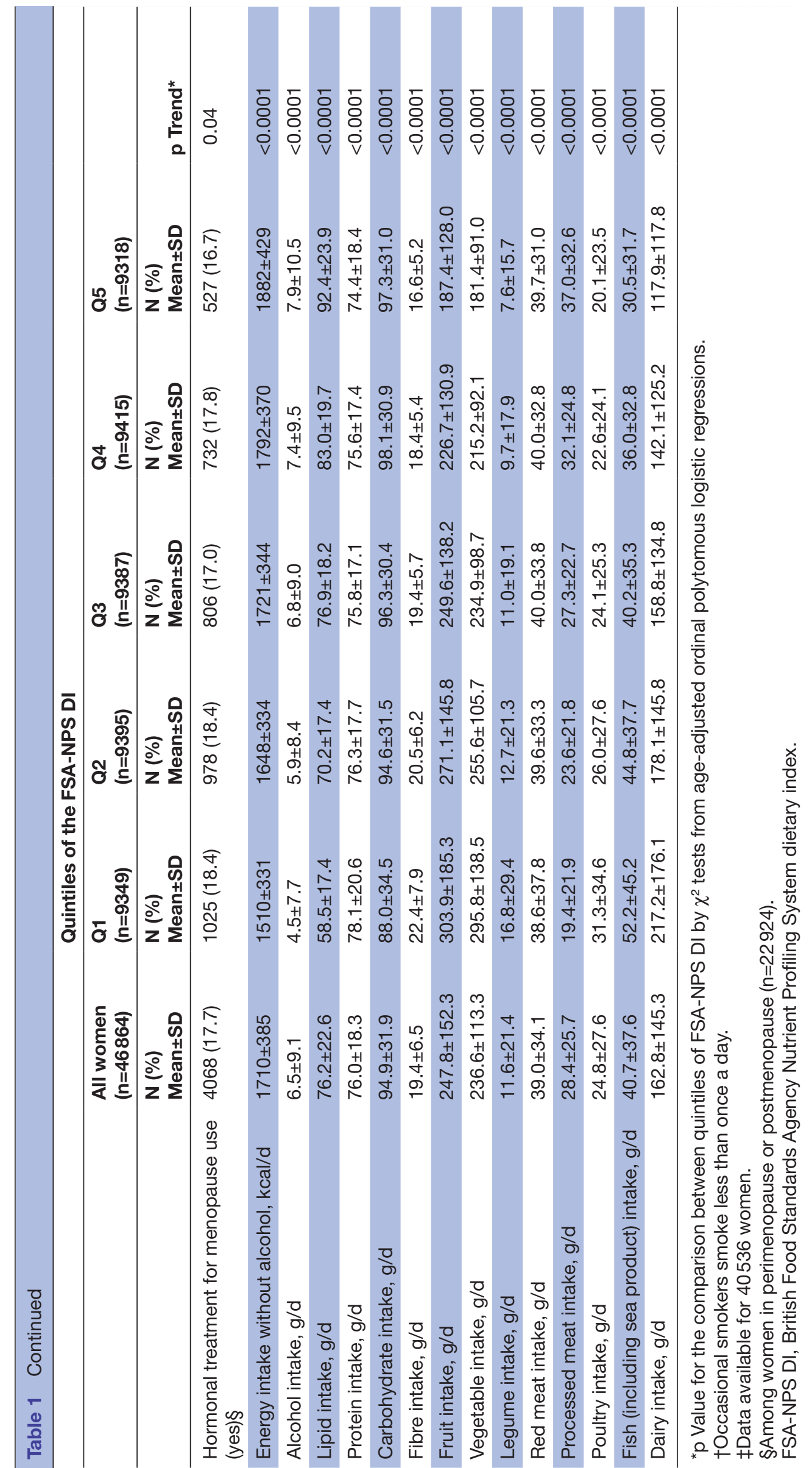


Table 2 Associations between the FSA-NPS DI and breast cancer risk, from multivariable Cox proportional hazards models, NutriNet-Santé Cohort, France, 2009-2015

\begin{tabular}{|c|c|c|c|c|c|c|c|}
\hline \multirow[b]{2}{*}{ FSA-NPS DI } & \multirow[b]{2}{*}{$\mathrm{N}$ for cases/non-cases } & \multicolumn{3}{|c|}{ Age-adjusted model } & \multicolumn{3}{|c|}{ Multivariable-adjusted model* } \\
\hline & & HR & $95 \% \mathrm{Cl}$ & p Trend & HR & $95 \% \mathrm{Cl}$ & p Trend \\
\hline \multicolumn{8}{|l|}{ Overall } \\
\hline Quintiles† & & & & 0.0004 & & & 0.002 \\
\hline Q1 & $82 / 9267$ & 1.00 & (ref) & & 1.00 & (ref) & \\
\hline Q3 & $117 / 9270$ & 1.45 & 1.09 to 1.93 & & 1.43 & $1.07,1.91$ & \\
\hline Q4 & $138 / 9277$ & 1.83 & 1.39 to 2.40 & & 1.79 & $1.35,2.38$ & \\
\hline Q5 & $96 / 9222$ & 1.56 & 1.15 to 2.10 & & 1.52 & $1.11,2.08$ & \\
\hline \multicolumn{8}{|c|}{ Premenopausal women $\ddagger$} \\
\hline Q2 & 28/3982 & 1.96 & 0.99 to 3.85 & & 1.92 & $0.97,3.79$ & \\
\hline Q3 & $31 / 4558$ & 1.94 & 0.99 to 3.78 & & 1.89 & $0.96,3.71$ & \\
\hline Q4 & $52 / 5204$ & 2.88 & 1.53 to 5.39 & & 2.76 & $1.45,5.26$ & \\
\hline Q5 & $48 / 6072$ & 2.52 & 1.34 to 4.76 & & 2.46 & $1.27,4.75$ & \\
\hline \multicolumn{8}{|c|}{ Postmenopausal women $\ddagger$} \\
\hline Continuous score & $384 / 27188$ & 1.06 & 1.01 to 1.11 & 0.02 & 1.05 & $1.00,1.11$ & 0.06 \\
\hline Quintiles† & & & & 0.03 & & & 0.09 \\
\hline Q1 & $70 / 6416$ & 1.00 & (ref) & & 1.00 & (ref) & \\
\hline Q2 & $94 / 6173$ & 1.35 & 0.99 to 1.84 & & 1.36 & $0.99,1.86$ & \\
\hline
\end{tabular}

${ }^{*}$ Models were adjusted for age (timescale), BMI ( $\mathrm{kg} / \mathrm{m}^{2}$, continuous), height (cm, continuous), physical activity (high, moderate and low), smoking status (never smokers, former smokers, occasional smokers and smokers), numbers of dietary records (continuous), alcohol intake (g/d, continuous), energy intake (without alcohol, g/d, continuous), family history of cancer (yes/no), educational level (<high school degree, $<2$ years after high school degree, $\geq 2$ years after high school degree), number of biological children (continuous), menopausal status at baseline (premenopause, perimenopause and postmenopause), hormonal treatment for menopause (postmenopausal women, yes/no) and oral contraception use (premenopausal women, yes/no).

†Cut-offs for quintiles of the FSA-NPS DI were 4.1/5.4/6.5/7.7.

$\neq p$ for interaction between the FSA-NPS DI and menopausal status $=0.06$.

BMI, body mass index; FSA-NPS DI, British Food Standards Agency Nutrient Profiling System dietary index.

level as a basis for the construction of the FSA-NPS DI at the individual level; the FSA-NPS was also recently used to define a variety score of 'healthier' and 'less healthy' foods/beverages (Ofcom binary cut-off used for advertising regulation in the $\mathrm{UK}^{12}$ ). This binary indicator was then studied in relation to mortality in the Whitehall II cohort. ${ }^{39}$ The authors observed that a greater variety of healthier foods, as defined with the FSA-NPS Ofcom binary cut-off, was associated with a reduced all-cause and cancer mortality while a greater variety of less healthy food was not associated with the studied outcomes. No association was observed when another nutrient profiling system, the SAIN,LIM, ${ }^{40}{ }^{41}$ was used. ${ }^{39}$

To our knowledge, the Overall Nutritional Quality Index (ONQI-f) is the only other dietary score based on a nutrient profiling system that has been studied in relation to health outcomes. ${ }^{42}$ It was tested in association with chronic diseases and mortality within the Nurses' Health Study and the Health Professionals Follow-up Study. ${ }^{42}$ A higher ONQI-f, reflecting a higher nutritional quality of the diet, was associated with a decreased risk of cardiovascular diseases, diabetes and mortality but was not associated with cancer. Some arguments may explain this lack of association: (1) the ONQI-f is based on 30 nutrients among which few have shown a consistent association with cancer risk, thus, its relevance regarding the cancer outcome may be lower than for other outcomes; (2) dietary intakes were assessed with an aggregated food frequency questionnaire (135-138 items), which provides less precise estimates than 24-hour dietary records (as used in our study). 
These studies are, to our knowledge, the only ones that investigated the associations between health outcomes and individual dietary indexes derived from nutrient profiling systems at the food level. Other a priori scores have been designed based on the intake of specific food groups or nutrients and/or other information (eg, body fatness and physical activity), but not based on a nutrient profiling system at the food/beverage level. These scores were studied prospectively in relation to breast cancer risk and provided relatively contrasted results: (1) scores measuring the adherence to a specific type of diet such as the Mediterranean diet score (no association in prospective cohorts, inverse association in case-control studies $^{43-45}$ ) or the Healthy Nordic Food Index (no association $\left.^{46}\right)$, (2) scores reflecting the adherence to general nutritional recommendations for the population such as the WHO Healthy Diet Index ${ }^{47}$ the Alternate Healthy Eating Index (AHEI) ${ }^{45} 48$ the Recommended Food Score (RFS) ${ }^{48}$ the Diet Quality Index revised ${ }^{48}$ or the Dietary Approaches to Stop Hypertension (DASH) ${ }^{45}$ (no association overall) and (3) scores measuring the adherence to cancer-specific nutritional recommendations such as the WCRF/AICR adherence score (inverse associations ${ }^{49}{ }^{50}$ ) or the American Cancer Society cancer prevention guidelines score (inverse association ${ }^{51}$ ). In these studies, differences according to hormonal receptor status of the tumours have been suggested, with inconsistent results. Indeed, inverse associations between a 'healthier' diet and breast cancer risk were particularly observed in ER- type (AHEI, RFS and aMed), ${ }^{48}$ ER-/PR+ type (Mediterranean diet score) ${ }^{43}$ and ER-/PR-/HER2+ type (DASH) ${ }^{45}$ but also with $\mathrm{ER}+/ \mathrm{PR}+$ type (WCRF/AICR adherence score) ${ }^{49}$ and ER+/PR- type ('healthy/Mediterranean' pattern).$^{52}$ In our study, information regarding hormonal receptor status of the tumours was only partially available, and the statistical power was limited in the analyses (online supplementary file 3 ), thus preventing to derive firm conclusions.

Overall, these studies involving a priori scores provided interesting insights into the relationships between nutrition and breast cancer risk. Although these a priori scores and the FSA-NPS DI included similar nutritional components, the approaches differed, making the comparison between our study and previous findings not straightforward (even though our results were in line with those obtained with scores measuring the adherence to cancer-specific nutritional recommendations ${ }^{49-51}$ ). The FSA-NPS DI is not primarily built at the individual level but is rather derived from a nutrient profiling system at the food level (FSA-NPS) thus taking into account the nutritional quality of each food/beverage consumed and not only of the overall diet or overall consumption of food groups. In addition, the objective behind the FSA-NPS DI construction was not to obtain the best predictive score for breast cancer but to specifically test its association with breast cancer risk, as the FSA-NPS is envisioned to serve as a basis for food labelling in the framework of public health policies in several countries such as France and
Australia. The FSA-NPS displays several key advantages in a public health context: (1) it grades the nutritional quality of each food/beverage and thus reflects the variation of nutritional quality between but also within food groups, (2) it has been designed in a perspective of prevention of a large range of chronic diseases (not only breast cancer) and (3) it is easy to compute for industrials and public health stakeholders.

Our results are consistent with current evidence from epidemiological and mechanistic studies regarding the association between nutrition and breast cancer. Most of the input variables for the FSA-NPS are indeed parameters for which associations with breast cancer have been established either directly (eg, dietary fibres ${ }^{53}$ ) or indirectly, through an association with body fatness, a major risk factor for postmenopausal breast cancer ${ }^{53-55}$ (eg, energy content, total sugars and SFA as components of energy-dense foods; fruits and vegetables as components of low-energy foods).

In our study, although similar trends were observed in premenopausal and postmenopausal women for the association between the FSA-NPS DI and breast cancer risk, this association was nonetheless stronger in premenopausal women. This may be explained by the fact that premenopausal women were more likely to score high on the FSA-NPS DI, thus resulting in a clearer/ stronger association: mean \pm SD FSA-NPS DI was $6.3 \pm 2.3$ in premenopausal women (median:6.4, 25th75th percentiles: $4.9-7.8)$ and $5.5 \pm 2.1$ in postmenopausal women (median:5.5, 25th75th percentiles: 4.1-6.9).

Strengths of this study pertained to its prospective design, its large sample size and the assessment of usual dietary intakes using repeated 24-hour dietary records based on a recent food composition database with a large choice of items $(>3300)$. The latter allowed a better insight into the food products consumed and their intrinsic nutritional quality compared with studies that used a food frequency questionnaire (more aggregated food items). However, some limitations should be acknowledged. First, caution is needed regarding the extrapolation of these results to the entire French population since this study included volunteers involved in a long-term cohort study investigating the association between nutrition and health, with overall more health-conscious behaviours and higher professional and/or educational level compared with the general population. Thus, unhealthy dietary behaviours may have been under-represented in this study, which may have weakened the observed associations. Second, information regarding cancer stage was not available. Third, unlike other a priori scores, components of the FSA-NPS DI cannot be studied separately since (1) the FSA-NPS DI is first calculated at the food level (FSA-NPS) and then aggregated at the individual level and (2) the calculation of the FSA-NPS score (online supplementary file 1) is based on thresholds and conditions that are inter-related between the different score components. Fourth, as usually done in nutritional epidemiology, dietary intakes were estimated based on averaged intakes 
from all 24-hour dietary records collected over the first 2 years of follow-up. Although diet may change over time, it is usually hypothesised that this estimation reflects general eating behaviour throughout the adult life. ${ }^{56}$ This very classical method allowed us to obtain a reliable estimation of usual dietary intakes, while respecting the prospective design (ie, estimation of usual dietary intakes prior to cancer diagnosis). Indeed, breast cancer is a disease with relatively long latency so that the involvement of nutritional factors is supposed to be based on long-term processes. Thus, it is important to guarantee sufficient delay between nutritional exposure and cancer outcome. This is why we tested a model (sensitivity analysis) where cancer cases diagnosed during the first year of follow-up were excluded (similar results). In our study, although the follow-up time was appropriate to perform etiological analyses, it did not necessarily guarantee this sufficient delay. Hence, our estimation of usual dietary intakes may reflect dietary protective and risk factors that may have played a role in the first steps of carcinogenesis (initiation) but also later in the carcinogenic process (progression). Nonetheless, previous studies with longer follow-up observed associations between diet and breast cancer risk, suggesting that nutritional factors could play a role in cancer initiation and not only in cancer progression. ${ }^{45}{ }^{48-52}$ Finally, this study was based on an observational cohort and thus residual confounding cannot be entirely ruled out even though a wide range of confounding factors were taken into account.

In conclusion, the FSA-NPS has been designed to characterise the nutritional quality of foodstuffs and to highlight products with a good nutritional profile that should be promoted and products with a lower nutritional quality that should not. The results of this observational study suggest that the self-declared consumption of food products of lower nutritional quality (as characterised by a higher FSA-NPS) may be associated with an increased risk of breast cancer. Along with other etiological observational studies, ${ }^{19-22}$ these findings suggest that this nutrient profiling system might be of interest in the framework of public health nutritional measures such as front-of-pack nutrition labelling or taxes.

Correction notice This paper has been amended since it was published Online First. Owing to a scripting error, some of the publisher names in the references were replaced with 'BMJ Publishing Group'. This only affected the full text version, not the PDF. We have since corrected these errors and the correct publishers have been inserted into the references.

Acknowledgements The authors would like to thank all the volunteers of the NutriNet-Santé cohort. We extend special thanks to Véronique Gourlet for the statistical analyses and to Nathalie Arnault, Stephen Besseau, Laurent Bourhis, Yasmina Chelghoum, Than Duong Van, Younes Esseddik, Paul Flanzy, Charlie Ménard, Mac Rakotondrazafy, Fabien Szabo, Roland Andrianasolo, Fatoumata Diallo, Cédric Agaesse, Claudia Chahine, Marion Genest and Ludivine Ursule for their technical contribution to the NutriNet-Santé study.

Contributors The authors contributions were as follows: MD and MT: designed the research; SH, MT, CJ and EK-G: conducted the research; MD and MT: supervised statistical analysis; MD and MT: wrote the paper; CJ, EK-G, LL, SA, CM, PD, SP, PL-M, LKF, PF, SH: contributed to the data interpretation and revised each draft for important intellectual content. All authors read and approved the final manuscript. MD and MT had primary responsibility for the final content.

Funding MD, PF and SA were funded by PhD grants from the Région lle-de-France (public funding: Cancéropôle lle-de-France and CORDDIM). The NutriNet-Santé study was supported by the following public institutions: Ministère de la Santé, Institut de Veille Sanitaire (InVS), Institut National de la Prévention etde l'Education pour la Santé (INPES), Région lle-de-France (CORDDIM), Institut Nationalde la Santé et de la Recherche Médicale (INSERM), Institut National de la Recherche Agronomique (INRA), Conservatoire National des Arts et Métiers (CNAM) and Université Paris 13. The funders had no role in the design, implementation, analysis or interpretation of the data.

Competing interests None declared.

Ethics approval IRB Inserm n0000388FWA00005831.

Provenance and peer review Not commissioned; externally peer reviewed.

Data sharing statement All relevant data are in the manuscript and its supporting files. No additional data available.

Open Access This is an Open Access article distributed in accordance with the Creative Commons Attribution Non Commercial (CC BY-NC 4.0) license, which permits others to distribute, remix, adapt, build upon this work non-commercially, and license their derivative works on different terms, provided the original work is properly cited and the use is non-commercial. See: http://creativecommons.org/ licenses/by-nc/4.0/

(C) Article author(s) (or their employer(s) unless otherwise stated in the text of the article) 2017. All rights reserved. No commercial use is permitted unless otherwise expressly granted.

\section{REFERENCES}

1. WHO/IARC. All cancers: estimated Cancer incidence, mortality and prevalence Worldwide in 2012. GLOBOCAN 2012, 2016. http:// globocan.iarc.fr/Pages/fact_sheets_cancer.aspx

2. WCRF/AICR. Cancer preventability estimates for food, nutrition, body fatness, and physical activity: WCRF/AICR, 2016. http://www. wcrf.org/int/cancer-facts-figures/preventability-estimates/cancerpreventability-estimates-diet-nutrition

3. Agency FS. Welsh Government, Scottish Government, Department of Health. front of Package Nutrition Labelling: joint response to consultation. 2013

4. Gill T, King L, Vita P, et al. A 'state of the knowledge' assessment of comprehensive interventions that address the drivers of obesity. A Rapid Assessment Prepared for the National Health and Medical Research Council (NHMRC). Sydney, The Boden Institute of Obesity, Nutrition, Exercise and Eating Disorders, University of Sydney, 2010.

5. Institute of Medecine. Front-of-package nutrition rating systems and symbols: promoting healthier choices. Washington, DC: The National Academies Press, 2012.

6. WHO. Action plan for the global strategy for the prevention and control of non-communicable diseases. Geneva: World Health Organization, 2009.

7. Europe WHO. Action Plan for implementation of the European Strategy for the Prevention and Control of Noncommunicable diseases 2012-2016. Copenhagen: World Health Organization Regional Office for Europe, 2011.

8. Arambepola C, Scarborough P, Rayner M. Validating a nutrient profile model. Public Health Nutr 2008;11:371-8.

9. Rayner M, Scarborough P, Stockley P, et al. Nutrient profiles: development of Final Model. Final Report [online]. London: FSA, 2005.

10. Hercberg S. Propositions pour un nouvel élan de la politique nutritionnelle française de santé publique dans le cadre de la stratégie nationale de santé. 1ère partie: mesures concernant La prévention nutritionnelle [in french], 2013.

11. Rayner M, Scarborough P, Stockley L. Nutrient profiles: applicability of currently proposed model for uses in relation to promotion of food to children aged 5-10 and adults. [online]. London: Foods Standard Agency, 2005.

12. Rayner M, Scarborough P, Lobstein T. The UK Ofcom Nutrient Profiling Model: defining 'healthy' and 'unhealthy' foods and drinks for TV advertising to children. London: OfCom, 2009.

13. Julia C, Kesse-Guyot E, Touvier M, et al. Application of the British Food Standards Agency nutrient profiling system in a French food composition database. Br J Nutr 2014;112:1699-705. 
14. Julia C, Kesse-Guyot E, Ducrot P, et al. Performance of a five category front-of-pack labelling system - the 5-colour nutrition labelto differentiate nutritional quality of breakfast cereals in France. BMC Public Health 2015;15:179.

15. Julia $C$, Ducrot $P$, Péneau $S$, et al. Discriminating nutritional quality of foods using the 5-Color nutrition label in the french food market: consistency with nutritional recommendations. Nutr J 2015;14:100

16. Haut Conseil de la Santé Publique. Avis relatif à l'information sur la qualité nutritionnelle des produits alimentaires. Paris: HCSP, 2015.

17. Julia C, Touvier M, Méjean C, et al. Development and validation of an individual dietary index based on the british Food Standard Agency nutrient profiling system in a french context. J Nutr 2014;144:2009-17.

18. Julia C, Méjean C, Touvier M, et al. Validation of the FSA nutrient profiling system dietary index in french adults-findings from SUVIMAX study. Eur J Nutr 2016;55.

19. Julia $C$, Ducrot P, Lassale $C$, et al. Prospective associations between a dietary index based on the british Food Standard Agency nutrient profiling system and 13-year weight gain in the Su.vi.max cohort. Prev Med 2015;81:189-94.

20. Julia C, Fézeu LK, Ducrot P, et al. The nutrient profile of foods consumed using the British food standards agency nutrient profiling system is associated with Metabolic syndrome in the SU.VI.MAX cohort. J Nutr 2015;145:2355-61.

21. Adriouch S, Julia C, Kesse-Guyot E, et al. Prospective association between a dietary quality index based on a nutrient profiling system and cardiovascular disease risk. Eur J Prev Cardiol 2016;23:1669-76.

22. Donnenfeld M, Julia C, Kesse-Guyot E, et al. Prospective association between cancer risk and an individual dietary index based on the british Food Standards Agency Nutrient Profiling System. Br J Nutr 2015;114:1702-10.

23. Hercberg S, Castetbon K, Czernichow S, et al. The Nutrinet-Santé Study: a web-based prospective study on the relationship between nutrition and health and determinants of dietary patterns and nutritional status. BMC Public Health 2010;10:242.

24. Vergnaud AC, Touvier M, Méjean C, et al. Agreement between webbased and paper versions of a socio-demographic questionnaire in the NutriNet-Santé study. Int J Public Health 2011;56:407-17.

25. Lassale C, Péneau S, Touvier M, et al. Validity of web-based selfreported weight and height: results of the Nutrinet-Santé study. $J$ Med Internet Res 2013;15:e152.

26. Touvier M, Méjean C, Kesse-Guyot E, et al. Comparison between web-based and paper versions of a self-administered anthropometric questionnaire. Eur J Epidemiol 2010;25:287-96.

27. Craig CL, Marshall AL, Sjöström M, et al. International physical activity questionnaire: 12 -country reliability and validity. Med Sci Sports Exerc 2003;35:1381-95.

28. Lassale C, Castetbon K, Laporte F, et al. Correlations between fruit, vegetables, fish, vitamins, and Fatty Acids estimated by Web-Based Nonconsecutive Dietary Records and Respective biomarkers of Nutritional Status. J Acad Nutr Diet 2016;116:427-38.

29. Lassale C, Castetbon K, Laporte F, et al. Validation of a Web-based, self-administered, non-consecutive-day dietary record tool against urinary biomarkers. Br J Nutr 2015;113:953-62.

30. Touvier M, Kesse-Guyot E, Méjean C, et al. Comparison between an interactive web-based self-administered $24 \mathrm{~h}$ dietary record and an interview by a dietitian for large-scale epidemiological studies. $\mathrm{Br} J$ Nutr 2011;105:1055-64.

31. Le Moullec N, Deheeger M, Preziosi P, et al. Validation Du Manuel photo utilisé pour l'enquête alimentaire de l'étude SU.VI.MAX. [Validation of the food portion size booklet used in the SU.VI.MAX study] (in French).. Cah Nutr Diet 1996;31:158-64.

32. Arnault N, Caillot L, Castetbon K, et al. Table De composition des aliments, étude NutriNet-Santé. [Food composition table, NutriNetSanté study] (in French). Paris: Les éditions INSERM/Economica 2013.

33. Black AE. Critical evaluation of energy intake using the Goldberg cut-off for energy intake:basal metabolic rate. A practical guide to its calculation, use and limitations. Int J Obes Relat Metab Disord 2000;24:1119-30.
34. Haut Conseil de la Santé Publique. Opinion on information regarding the nutritional quality of foodstuffs. Paris: HCSP, 2015.

35. WHO. ICD-10, International classification of diseases and related health problems. 10th revision. Geneva, Switzerland: World Health Organization, 2010.

36. CépiDC I. Interrogation des données sur les causes de décès de 1979 à 2013. Inserm 2016http://www.cepidc.inserm.fr/inserm/html/ index2.htm.

37. INCa. Incidence et mortalité estimées par classe d'âge et par localisation cancéreuse en 2012. 2016.

38. IPAQ Group. Guidelines for data processing and analysis of the International Physical Activity Questionnaire (IPAQ). 2005.

39. Masset G, Scarborough P, Rayner M, et al. Can nutrient profiling help to identify foods which diet variety should be encouraged? results from the Whitehall II cohort. Br J Nutr 2015;113:1800-9.

40. Afssa. Définition de profils nutritionnels pour l'accès aux allégations nutritionnelles et de santé: propositions et arguments [The setting of nutrient profiles for access to nutrition an health claims: proposals and arguments] (in French). 2008. Paris, Agence française de sécurité des aliments.

41. Darmon N, Vieux F, Maillot M, et al. Nutrient profiles discriminate between foods according to their contribution to nutritionally adequate diets: a validation study using linear programming and the SAIN, LIM system. Am J Clin Nutr 2009;89:1227-36.

42. Chiuve SE, Sampson L, Willett WC. The association between a nutritional quality index and risk of chronic disease. Am J Prev Med 2011;40:505-13.

43. Schwingshackl L, Hoffmann G. Adherence to mediterranean diet and risk of cancer: an updated systematic review and meta-analysis of observational studies. Cancer Med 2015;4:1933-47.

44. Schwingshackl L, Hoffmann G. Does a mediterranean-type diet reduce cancer risk? Curr Nutr Rep 2016;5:9-17.

45. Hirko KA, Willett WC, Hankinson SE, et al. Healthy dietary patterns and risk of breast cancer by molecular subtype. Breast Cancer Res Treat 2016;155:579-88.

46. Li Y, Roswall N, Sandin S, et al. Adherence to a healthy nordic food index and breast cancer risk: results from a swedish cohort study. Cancer Causes Control 2015;26:893-902.

47. Cade JE, Taylor EF, Burley VJ, et al. Does the mediterranean dietary pattern or the healthy Diet Index influence the risk of breast cancer in a large british cohort of women? Eur J Clin Nutr 2011;65:920-8.

48. Fung $\mathrm{TT}$, Hu FB, McCullough ML, et al. Diet quality is associated with the risk of estrogen receptor-negative breast cancer in postmenopausal women. J Nutr 2006;136:466-72.

49. Harris HR, Bergkvist L, Wolk A. Adherence to the World cancer research Fund/American Institute for cancer research recommendations and breast cancer risk. Int $J$ Cancer 2016;138:2657-64

50. Nomura SJ, Inoue-Choi M, Lazovich D, et al. WCRF/AICR recommendation adherence and breast cancer incidence among postmenopausal women with and without non-modifiable risk factors. Int J Cancer 2016;138:2602-15.

51. Thomson CA, McCullough ML, Wertheim BC, et al. Nutrition and physical activity cancer prevention guidelines, cancer risk, and mortality in the women's health initiative. Cancer Prev Res 2014;7:42-53.

52. Cottet V, Touvier M, Fournier A, et al. Postmenopausal breast cancer risk and dietary patterns in the E3N-EPIC prospective cohort study. Am J Epidemiol 2009;170:1257-67.

53. Latino-Martel P, Cottet V, Druesne-Pecollo N, et al. Alcoholic beverages, obesity, physical activity and other nutritional factors, and cancer risk: a review of the evidence. Crit Rev Oncol Hematol 2016;99[308:323.

54. WCRF/AICR. Food, nutrition, physical activity and the prevention of cancer: a global perspective. Washington, DC: AICR, 2007.

55. WCRF/AICR. Systematic Iterature review-continuous update project report: the associations between food, nutrition and physical activity and the risk of breast cancer. Washington, DC: AICR, 2010.

56. Willett WC. Nutritional epidemiology, 2nd ed. New York: Oxford University Press, 1998. 